\title{
The work-study interface: similarities and differences between ethnic minority and ethnic majority students
}

\author{
Marieke Meeuwisse ${ }^{1} \cdot$ Lonneke A. L. de Meijer ${ }^{1}$ • \\ Marise Ph. Born ${ }^{1} \cdot$ Sabine E. Severiens ${ }^{1}$
}

(C) Springer Science+Business Media Dordrecht 2016

\begin{abstract}
Given the poorer academic outcomes of non-Western ethnic minority students compared to ethnic majority students, we investigated whether differences exist in workstudy interface between ethnic groups. We tested a work-study interface model, in which the work-related factors work-study congruence, job control, job demands, work hours, job involvement and job support were antecedents to work-study facilitation (WSF) and workstudy conflict (WSC). WSC and WSF, in turn, were expected to predict students' study effort and subsequently students' grades. This model fitted well for the full sample and both non-Western ethnic minority students $(N=167)$ and ethnic majority students $(N=666)$ separately at a large Dutch university. Results showed that work-study congruence, job control, job involvement and job support led to WSF, which in turn led to more study effort and higher grades. Job control decreased WSC and both job demands and the number of work hours increased WSC. WSC was negatively associated with study effort which resulted in lower grades. These structural relationships, as depicted in the conceptual model of work-study interface, were similar for both the group of non-Western ethnic minority students and the group of ethnic majority students. However, ethnic minority students worked more hours per week than ethnic majority students, which partly explained-via WSC and study effort-the lower academic outcomes for this group.
\end{abstract}

Keywords Role combination · Work-study interface · Academic success · Higher education · Ethnicity

Marieke Meeuwisse and Lonneke A.L. de Meijer have contributed equally to this paper.

Marieke Meeuwisse

meeuwisse@fsw.eur.nl

$\square$ Lonneke A. L. de Meijer

demeijer@fsw.eur.nl

1 Department of Psychology, Education and Child Studies, Erasmus University Rotterdam, P.O. Box 1738, 3000 DR Rotterdam, the Netherlands 


\section{Introduction}

In the last few decades, the student population in Western societies has become ethnically diverse (e.g., Pryor et al. 2007; Richardson 2008; see also Meeuwisse et al. 2014). However, the chances for success in higher education seem not similar for ethnic groups of students as several studies demonstrated that the study careers of students from an ethnic minority background on average are less successful compared to the study careers of ethnic majority students (e.g., Hobson-Horton and Owens 2004; Richardson 2008; Severiens and Wolff 2008; Swail et al. 2003). Another development in higher education is that after-school engagement in employment has been increasing steadily for some decades (Beerkens et al. 2011; Butler 2007; Callender 2008; Creed et al. 2015; Derous and Ryan 2008; Riggert et al. 2006). Both internationally as well as in the Netherlands, the large majority of college students are employed [e.g., $74 \%$ in 2004 in the U.S. (U.S. Department of Education 2006), $72 \%$ in 2007 in Australia (Creed et al. 2015) and $67 \%$ in the Netherlands in 2012 (Van der Burg et al. 2012)]. This means that many students combine their role as a university student with a second role, namely paid employment.

In recent decades, many studies have been conducted on the combination of different roles. While in earlier studies the underlying assumption has been that one role is made more difficult by another role and vice versa (i.e., work-school conflict; e.g., Markel and Frone 1998), more recent studies propose that combining multiple roles may have a positive side (i.e., work-school facilitation; e.g., Butler 2007; Creed et al. 2015). In his study among undergraduate students Butler (2007) showed for example that job characteristics (e.g., job control) were related to work-school conflict (WSC) as well as workschool facilitation (WSF). To our knowledge, little research has been carried out on existing similarities and differences related to ethnicity in multiple role conflict and facilitation (see Meeuwisse et al. 2014). As Butler (2007) recognized, his sample was relatively homogeneous with little ethnic diversity. In the present study, therefore, we investigated possible differences in the work-study interface between ethnic groups of students in the Netherlands as a possible explanation for the poorer academic careers of non-Western ethnic minority students compared to the academic careers of ethnic majority students (e.g., Hobson-Horton and Owens 2004; Severiens and Wolff 2008; Swail et al. 2003). It is important to note that in the Netherlands the distinction between ethnic majority and ethnic minority is defined by the birthplace of one's parents (Statistics Netherlands). If at least one parent was born outside the Netherlands an individual belongs to an ethnic minority group (Statistics Netherlands).

\section{The work-study interface}

When the demands of a role one performs are incompatible with the demands of another, tension in the form of inter-role conflict is experienced (Kahn et al. 1964). According to Butler (2007), much student employment research is based on this assumption of resource scarcity in which potential resources (e.g., time, energy) are viewed as finite. As a consequence of using finite resources to fulfill the demands of one role resource availability for other roles will be reduced, constraining performance in those roles. For example, Markel and Frone (1998) suggested that conflict between work and school (i.e., work-study conflict) occurs when work requires time away from school-related activities or when work creates strain that impedes school performance. More recently, it has been proposed thatin contrast to the assumption of conflicting life domains-one role domain may offer 
resources that can be utilized in another role domain, leading to inter-role facilitation (Barnett and Hyde 2001; Butler 2007; Creed et al. 2015; Greenhaus and Powell 2006; Meeuwisse et al. 2011). In their recent study Creed et al. (2015) for example demonstrated that enabling resources, such as skills learned at work that aid performance at school, are positively related to work-study facilitation which ultimately leads to increased engagement and wellbeing. Derous and Ryan (2008) found similar results. They reported that job autonomy and relevance had a positive influence on study attitude and well-being. In sum, these findings illustrate that working may be beneficial for students and that, more specifically, certain job characteristics can enhance school outcomes.

The conceptual model of the work-study interface which guided the present research is presented in Fig. 1. We defined the work-study interface as the extent to which students' jobs affect their ability to meet study related demands and responsibilities in both a positive (i.e., work-study facilitation (WSF)) and a negative (i.e., work-study conflict (WSC)) way. In modelling the antecedents and outcomes of the work-study interface, we drew on models of the work-school interface (Butler 2007; Creed et al. 2015; Markel and Frone 1998), the work-family interface (Ford et al. 2007) and the family-study interface (Meeuwisse et al. 2011).

\section{Antecedents of the work-study interface}

Butler's (2007) study on the work-study interface revealed that congruence between students' job and their course program is positively associated with work-study facilitation (WSF). Experienced job control also showed a positive association with WSF (Butler 2007). Creed et al. (2015) demonstrated that job involvement was positively related to WSF. This means that the more students were involved at work the more WSF they experienced. From research on the combination of the work role and the family role it is known that social support at work forms a resource that contributes to work-family facilitation (Wayne et al. 2007). Meeuwisse et al. (2011) demonstrated that family social

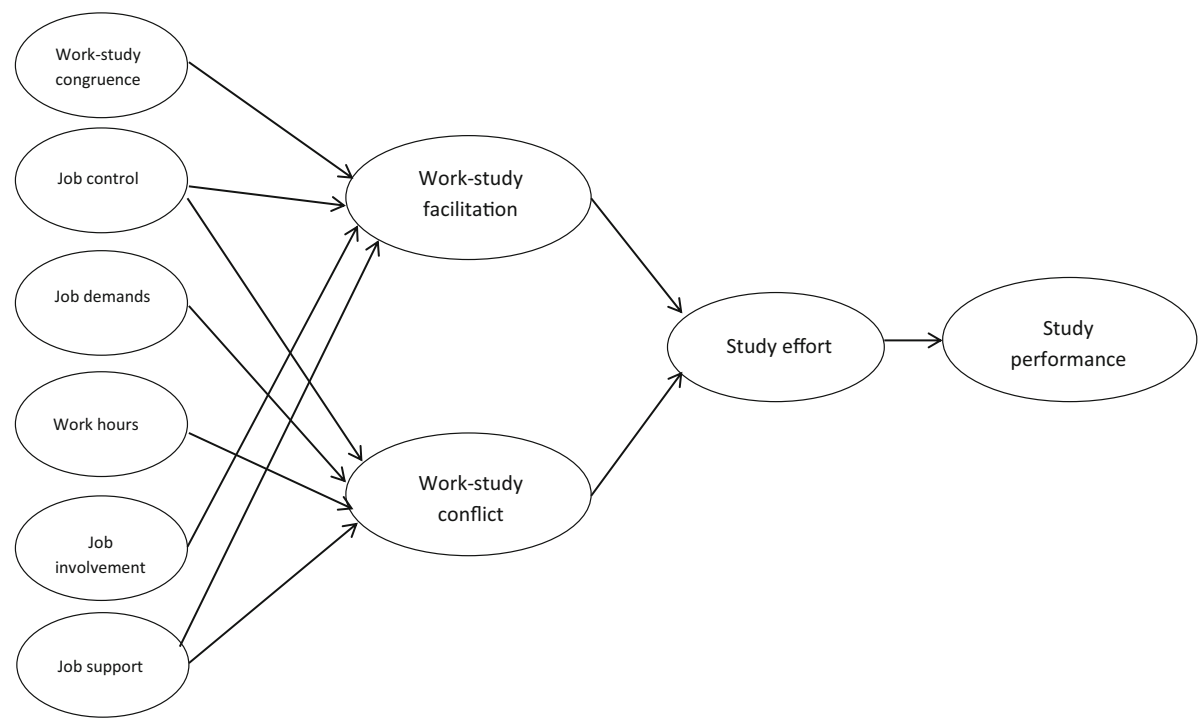

Fig. 1 Conceptual path model of WSC and WSF 
support positively affects family-study facilitation. In line with these results, we expected work-study congruence, job control, job involvement and job support to positively affect WSF (see Fig. 1).

The antecedents of work-study conflict (WSC) in our model were derived from earlier studies on (antecedents of) WSC. From Butler's (2007) study it is known that job control decreases WSC. Job demands (Butler 2007) and work hours (Butler 2007; Creed et al. 2015; Markel and Frone 1998) are positively associated with WSC. The meta-analysis of Ford et al. (2007) demonstrated that social support reduces conflict between roles. More specifically, job support is negatively associated with work-family conflict, and family support is negatively associated with family-work conflict. In a study on the family-study interface (Meeuwisse et al. 2011) a negative association was found between family support and family-study conflict. In line with these results, we expected job control and job support to negatively affect WSC, and job demands and job hours to positively affect WSC (see Fig. 1).

\section{The work-study interface and academic outcomes}

Our model (Fig. 1) outlines hypothesized relations between two study-related outcomes, namely study effort and students' grade point average (GPA). In line with prior research on the work-study interface, we expected a positive relationship between WSF and academic performance (e.g., study effort), and a negative relationship between WSC and academic performance (e.g., study effort) (Butler 2007). On the basis of studies which have demonstrated that study effort is a positive predictor of academic performance (Hofman and Van den Berg 2003, Markel and Frone 1998) we expected a positive relationship between study effort and students' GPA.

\section{The work-study interface and ethnic groups}

In previous research on multiple role conflict and facilitation, possible differences related to ethnicity have seldom been investigated. Meeuwisse et al. (2014) conducted one of the few studies into the generalizability of their model on the family-study interface across ethnic groups in the Netherlands. They reported more family-study conflict for ethnic minority students than ethnic majority students, resulting in less effortful study behaviors and lower academic outcomes in the ethnic minority group. With regard to the work-study interface (Butler 2007) and Butler's relatively homogeneous sample, it would be interesting to test the work-study interface model in a more diverse sample.

The largest (non-Western) ethnic minority groups in the Netherlands are from former Dutch Antillean descent, Moroccan, Surinamese, and Turkish descent. Migration of ethnic minority groups into the Netherlands existed for centuries before 1900, however, it increased massively after WWII (Hoving et al. 2005; Vogel 2005). During the 1950s, more and more non- or semi-skilled workers were required in the Netherlands. Especially from 1960 onwards, Dutch government and businesses started actively enlisting migrant workers from the Mediterranean, especially from Turkey and Morocco (Jennissen 2011; Lucassen 2005; Lucassen and Penninx 1994). In the beginning of the 1970s, a large number of colonial and non-colonial migrants started to migrate to the Netherlands. Migration occurred especially from Surinam, as Surinam became independent from the Netherlands in 1975 and a conflict between different sections of the Surinamese population became more and more visible. Also around this time, a relatively large number of people from the former Dutch Antilles came to the Netherlands (although smaller in number than the 
numbers of Moroccans, Surinamese, and Turks; Lucassen 2005; Lucassen and Penninx 1994). In these days, the immigrant population consisted predominantly of first-generation parents and their children (Eldering 1997). In 1979 the Dutch government created a minority policy to prevent migrants from the former colonies and Mediterranean countries from remaining in a low position in society over a long period of time. This minority policy resulted from the acknowledgment of the fact that many minorities decided to settle in the Netherlands, contrary to the expectation that they would return to their countries of origin. In reaction to this policy, Statistics Netherlands developed a monitoring system which assesses yearly the social position of ethnic minorities (Eldering 1997). It was because of this monitoring system that all government-funded institutions and factories had to register the numbers of employees born outside the Netherlands they employ. Today, Statistics Netherlands still defines ethnic background by the birthplace of one's parents.

Although the non-Western ethnic minority groups in the general population in the Netherlands are dissimilar in origin, they face comparable issues such as lower educational achievement and higher unemployment rates than ethnic majorities (Statistics Netherlands 2014). Analogous to the general working population (Statistics Netherlands 2014), ethnic minority students may be more compelled to work in addition to their study than ethnic majority students. Jennissen (2006) for example reported that ethnic minority students may work more hours besides their study (maybe due to less financial resources) compared to ethnic majority students. In a similar way, Kuh et al. (2006) state that ethnic minority students may be more likely to take additional jobs for financial reasons. Due to this stronger financial necessity, ethnic minority students seem to work longer hours and report less relevant work-related experiences, such as work-related supervisory positions and achievement (Hiemstra et al. 2013; Warren et al. 2000). Aside from these studies on average differences and experiences, as far as we know, up until now no prior research has been done into possible differences in the work-study interface related to ethnicity. In the present study, therefore, we will focus on the role of work in ethnic minority students' life and ethnic majority students' life in the Netherlands as a possible explanation for the poorer study results of ethnic minority students compared to ethnic majority students (e.g., Hobson-Horton and Owens 2004; Severiens and Wolff 2008; Swail et al. 2003).

We aim to investigate (1) possible mean differences between ethnic minority and ethnic majority students in WSC and WSF, and (2) possible differences in the relationship between this work-study interface and academic outcomes in both groups of students. We combined the conceptual models of the work-study interface of Butler (2007) and of the family-study interface of Meeuwisse et al. (2011) in one model (see Fig. 1). In this model the work-study interface is defined as the extent to which work affects the ability of students to meet study-related demands and responsibilities in both a positive (i.e., facilitation) and a negative (i.e., conflict) way.

For the present study the question was formulated whether the work-study model on multiple role conflict and facilitation would hold true for both ethnic groups and whether the model would be invariant across ethnic groups. More specifically, we formulated the following research questions (RQ):

RQ1: Do ethnic minority and ethnic majority students differ in terms of (antecedents of) work-study conflict (WSC) and work-study facilitation (WSF)?

RQ2: Does the model as depicted in Fig. 1 hold true for both ethnic minority and ethnic majority students?

RQ3: Are the structural relations in the model as depicted in Fig. 1 different for ethnic minority and ethnic majority students? 


\section{Method}

\section{Participants and procedure}

In the spring of the 2007/2008 academic year students from a large university in the western part of the Netherlands were invited to fill out an online questionnaire measuring conflict and facilitation between life domains, possible antecedents of conflict and facilitation and academic outcomes (study effort). They were solicited via the university's study information network and via an e-mail announcement, and were able to win one of five IPods. For the present study investigating the work-study interface, ${ }^{1}$ we included 833 students who were combining their academic studies with a job and for whom we were able to calculate the congruence between their academic studies and their job (i.e. workstudy congruence). Fifty-three percent of the participants were women, the average age was 22.13 years $(\mathrm{SD}=2.80)$ and $20 \%$ of the respondents $(n=167)$ belonged to a nonWestern ethnic minority group (Table 1). The distinction between ethnic majority and ethnic minority students was drawn based on the definition used by Statistics Netherlands. According to the Statistics Netherlands, an individual belongs to an ethnic minority group if at least one parent was born outside the Netherlands. The minority students in our sample belonged to a non-Western minority group, as the student respondent or one or both parents were born in the former Dutch Antilles (2.3\%), in Morocco (1.7\%), Surinam (5.9\%), Turkey $(2.2 \%)$, or another non-Western country $(8.0 \%)$. Unfortunately it was not possible to distinguish between these non-Western ethnic groups in our analyses as these subgroups were represented by relatively small samples.

\section{Measures}

Each participant completed an online version of a questionnaire measuring conflict and facilitation between the work domain and the study domain (WSC and WSF), possible antecedents of conflict and facilitation (namely work-study congruence, job control, job demands, work hours, job involvement and job support), and academic outcomes (study effort) on a five-point rating scale ranging from 1 (not true at all) to 5 (completely true). Participants provided their identification numbers so GPAs could be obtained from the official university records. All measures showed good reliability estimates in our sample (see Table 1).

\section{Work-study congruence}

Work-study congruence was measured asking students in what employment area they were working, followed by a question on their specific position. Both employment sector and employment level were used, in combination with students' course program, to estimate the congruence between a student's job and course program from 1 (little congruence between work and study) to 3 (large congruence between work and study).

\footnotetext{
${ }^{1}$ Former papers on the family-study interface (Meeuwisse et al. 2011, 2014) also made use of this same dataset. The present paper expands on these previous studies by focusing on the combination of work and study in the lives of ethnic minority and ethnic majority students in higher education.
} 


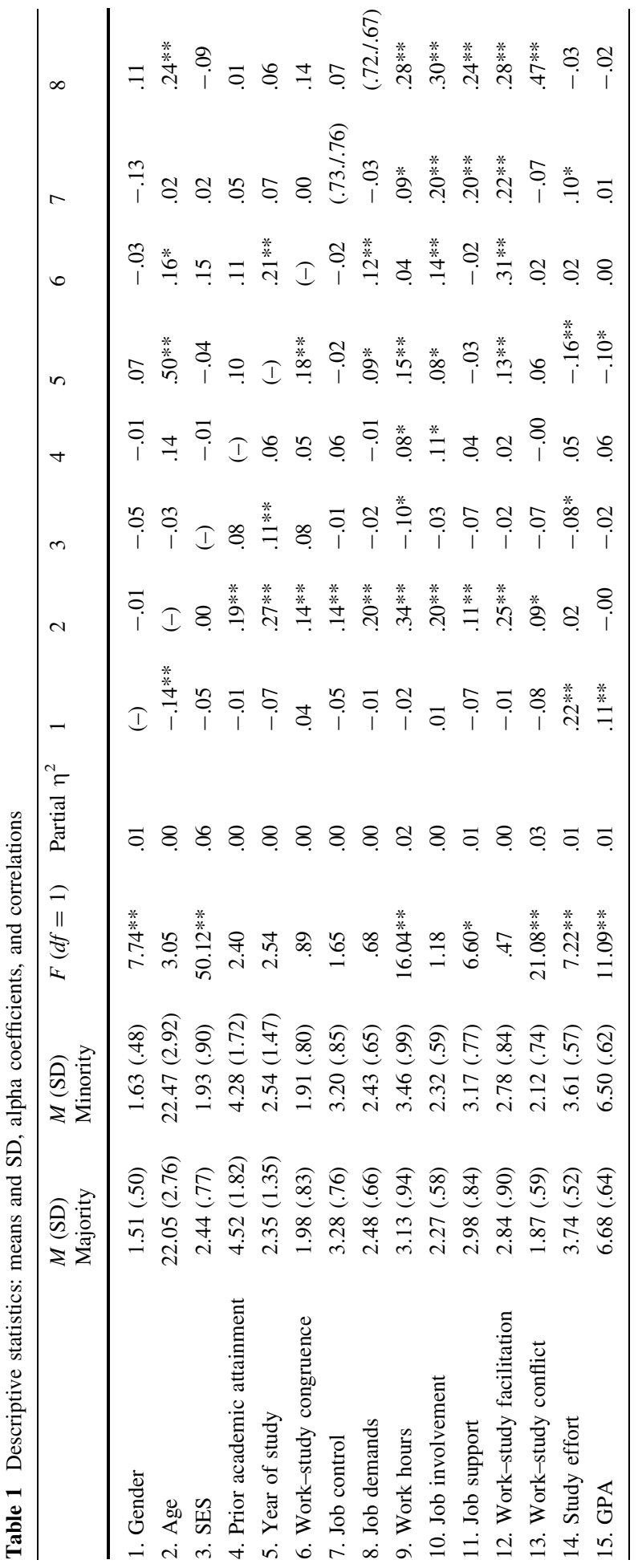




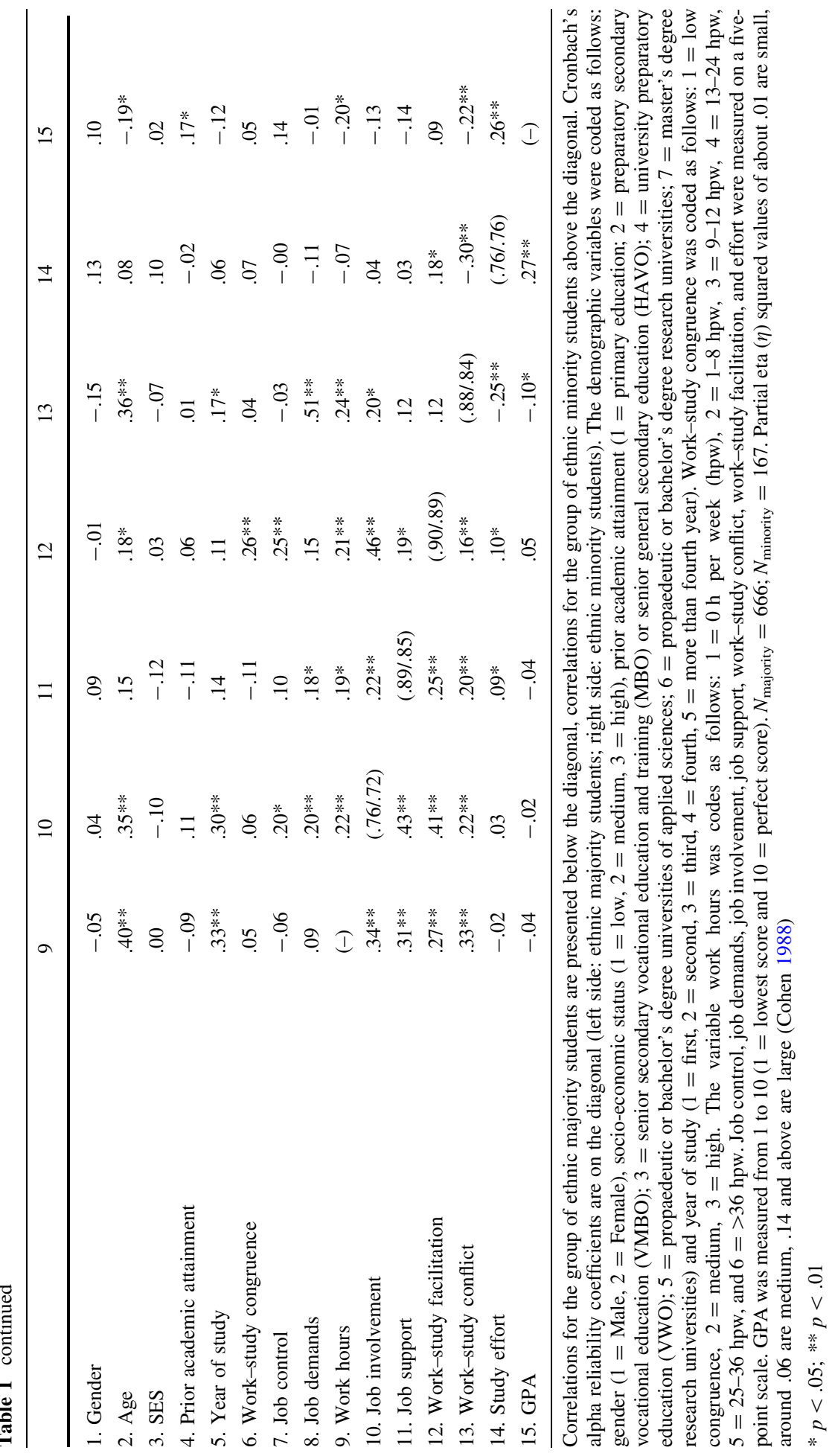




\section{Job control}

Job control refers to autonomy over decision making and how work is accomplished (Butler 2007). We assessed job control with three items from Butler's (2007) job control scale and one item developed for the present study (see appendix for individual scale items).

\section{Job demands}

Job demands were measured using the six items from the job demands scale (Butler 2007). These items reflect job demands such as quantity of work, temporal constraints and conflicts (Butler 2007).

\section{Work hours}

Using a single item, respondents were asked how many hours per week they worked on average from 1 ( 0 h per week) to 6 ( $>36$ h per week).

\section{Job involvement}

Job involvement was assessed using six out of nine job involvement items (Reeve and Smith 2001), asking respondents to report the extent to which they are involved in their work.

\section{Job support}

Job support was assessed by modifying eight items from the Perceived Social Support from the Family Scale (Procidano and Heller 1983) so that these referred to respondents' job. All items reflect perceived support from colleagues.

\section{Work-study facilitation}

Work-study facilitation was assessed using nine items developed for the present study, partly adapted from measures of work-study facilitation (Butler 2007) and measures of work-family facilitation (Butler et al. 2005; cf. Meeuwisse et al. 2011, 2014). All items reflect facilitation from work to study.

\section{Work-study conflict}

Work-study conflict was measured using thirteen items reflecting conflict from work to study developed for the present study. The individual scale items were adapted from measures of work-study conflict (Butler 2007) and work-family conflict (Carlson et al. 2000) (cf. Meeuwisse et al. 2011, 2014).

\section{Study effort}

Students' study effort was measured using the nine-item study-effort scale used by Butler (2007). The items reflect effortful study behaviors, such as concentrating in class and studying hard for exams. 


\section{Academic performance}

The students' cumulative GPA served as measure of academic performance. The data were obtained from the academic records of the university in the second semester of the 2007/2008 academic year, which was the semester of the data collection (see also Meeuwisse et al. 2011, 2014).

\section{Demographic variables}

Five demographic variables were included as covariates in the model, i.e., gender ( 1 = male, 2 = female), age (in years), socio-economic status (low, medium, high), prior academic attainment $(1=$ primary education; $2=$ preparatory secondary vocational education (VMBO); 3 = senior secondary vocational education and training (MBO) or senior general secondary education (HAVO); $4=$ university preparatory education (VWO); $5=$ propaedeutic or bachelor's degree universities of applied sciences; $6=$ propaedeutic or bachelor's degree research universities; $7=$ master's degree research universities), year of study (first-year student, second-year student, third-year student, fourth-year student and fifth-year student or longer). These five demographic variables were self-reported as well as the demographic variable ethnicity.

\section{Analyses}

\section{Preliminary analyses}

Using Amos 20.0 (IBM SPSS Amos 2011), configural invariance (i.e., conceptual equivalence of measures) and metric invariance (i.e., equivalent calibration of measures to constructs) of all measures were checked across ethnic groups before conducting any further analyses (Vandenberg and Lance 2000; see also Meeuwisse et al. 2014). Following guidelines detailed by Byrne (2001), it was first tested whether the pattern of factor loadings imposed on the measures' items was equivalent across groups (i.e., configural invariance), followed by testing whether the factor loadings of the measures' items were equal (i.e., metric invariance) across groups (Vandenberg and Lance 2000; see also Meeuwisse et al. 2014). One WSC item showed to be variant across ethnic groups and was removed from further analyses.

\section{Research analyses}

Controlling for gender, age, socio-economic status (SES), and year of study, analyses of variance (MANOVA) were conducted to answer $R Q 1$, namely whether there were any mean differences between ethnic majority and non-Western ethnic minority students with regard to the possible antecedents of WSC and WSF (namely work-study congruence, job demands, control, involvement, support, work hours), WSC and WSF, study effort and academic performance (i.e., GPA). We controlled for categorical variables (such as gender) by putting these in the analyses as fixed factors, and we controlled for continuous variables (such as age) by putting these in the analyses as covariates.

The hypothesized structural path model was estimated using structural equation modeling (Arbuckle and Wothke 1999). In addition to $\chi^{2}$, we used the comparative fit index (CFI), with a cut-off value of $>.95$ (Hu and Bentler 1999) and the root mean square 
error of approximation (RMSEA), with guidelines proposed by MacCallum et al. (1996). RMSEA values of less than .05 indicate a close fit, values ranging from .05 to .08 a fair fit, values from .08 to .10 a mediocre fit and values exceeding .10 a poor fit between the observed data and the specified theoretical model (see also Meeuwisse et al. 2011, 2014). To obtain modification indices for model fit missing values were replaced by the linear trend at point. After model fit was obtained for the full sample, it was examined whether these results were invariant across ethnic background ( $R Q 2$ and $R Q 3)$. For this purpose, both within and between-group analyses were conducted (see Byrne 2004, for this procedure; cf. Tang et al. 2012).

\section{Results}

Table 1 presents the descriptive statistics ( $M$ and $S D s)$ and intercorrelations among all variables, separately for ethnic majority and non-Western ethnic minority students. Cronbach alphas of the scales ranged from .72 to .90 for the group of ethnic majority students and from .67 to .89 for the group of ethnic minority students, and are provided on the diagonal. All variables are scored such that a high score represents higher levels of the construct. Results showed that both ethnic majority students and ethnic minority students more often experienced facilitation between their work lives and their lives as a student than conflict between these two domains.

Model fit was assessed for the conceptual model excluding covariates as well as the conceptual model including covariates (cf. Butler 2007). The analysis revealed that the demographic covariates had virtually no impact on the magnitude of the parameter estimates. Consequently, the covariates were dropped from the further model estimation analyses (cf. Frone et al. 1992; Meeuwisse et al. 2014 for this procedure).

\section{Mean differences between ethnic majority and non-Western ethnic minority students}

Investigating $R Q 1$, analyses of variance (MANOVA) were conducted to examine possible mean differences between ethnic majority students and non-Western ethnic minority students with regard to the following variables: work-study congruence, job control, job demands, work hours, job involvement, job support, WSF, WSC, study effort, and academic performance (i.e., GPA). The analyses controlled for gender, age, SES, prior academic attainment and year of study (see Table 2).

Results are shown in Table 2 and revealed that ethnic minority students reported a longer work week than ethnic majority students. Ethnic majority students reported a higher level of job demands compared to ethnic minority students. No significant differences between ethnic groups were found with regard to work-study congruence, job control, job involvement and job support. Furthermore, results showed that ethnic minority students perceived more WSC than ethnic majority students. No significant difference was found between ethnic groups on WSF. Finally, results revealed that ethnic minority students reported less study effort and earned lower grades than did ethnic majority students. 
Table 2 Analyses of variance (MANOVA): differences according to ethnic background

\begin{tabular}{|c|c|c|c|c|}
\hline & $d f$ & $F$ & Partial $\eta^{2}$ & $R^{2}$ \\
\hline Analysis 1: job characteristics & 6 & $2.89 * *$ & .02 & \\
\hline \multicolumn{5}{|l|}{ Between subjects } \\
\hline WS congruence & 1 & 1.82 & .00 & .07 \\
\hline Job control & 1 & 1.49 & .00 & .03 \\
\hline Job demands & 1 & $3.91 *$ & .01 & .06 \\
\hline Work hours & 1 & $6.71 *$ & .01 & .16 \\
\hline Job involvement & 1 & .01 & .00 & .07 \\
\hline Job support & 1 & 1.26 & .00 & .03 \\
\hline Analysis 2 : work-study interface & 2 & $7.01 * *$ & .02 & \\
\hline \multicolumn{5}{|l|}{ Between subjects } \\
\hline WSF & 1 & 1.15 & .00 & .07 \\
\hline WSC & 1 & $11.33 * *$ & .02 & .07 \\
\hline Analysis 3: academic outcomes & 2 & $6.78 * *$ & .02 & \\
\hline \multicolumn{5}{|l|}{ Between subjects } \\
\hline Effort & 1 & $8.61 * *$ & .01 & .08 \\
\hline GPA & 1 & $8.42 * *$ & .01 & .05 \\
\hline
\end{tabular}

Partial eta $(\eta)$ squared values of about .01 are small, around .06 are medium and .14 or above are large (Cohen 1988)

$* p<.05 ; * * p<.01$

\section{Model evaluation for the full sample}

Structural equation modeling was used to determine the interrelationships between workstudy congruence, job control, job demands, work hours, job involvement, job support, WSF, WSC, study effort and academic performance. Covariances between the work variables (i.e., the independent variables work-study congruence, job control, job demands, work hours, job involvement and job support) had to be drawn to obtain model fit. This resulted in the following values for the full sample $(N=833): \chi^{2}=55.52, d f=19, p<.01$; CFI $=.97$; $\mathrm{RMSEA}=.05$. Despite the significance of the $\chi^{2}$-value, the other fit measures indicated that the model fits well. Accordingly, the proposed model could be accepted.

\section{Multiple group comparisons}

For the purpose of testing whether the model obtained from the full sample was invariant across ethnic background ( $R Q 2$ and $R Q 3)$, within and between-group models were specified. The results of these analyses are provided in Table 3. Results showed that the model fits well for both ethnic majority and non-Western ethnic minority students (RQ2). In other words, the model in Fig. 1 holds true for both groups of students. Participations in work activities affect both WSC and WSF. More specifically, the more students worked, the more WSC they experienced. Perception of job control was negatively related to WSC (which means that more job control is related to less WSC) and positively to WSF (which means that more job control is related to more WSF). Job demands were found to be positively related to WSC, showing that the more demands students experienced in their job, the more conflict they felt between their work and study. Job involvement and job 
support were positively related to WSF. Work-study congruence showed a positive relationship with WSF, indicating that the more students experienced congruence between their job and course program, the more facilitation they reported between their work and study. Furthermore, WSC and effort were negatively related, indicating that the more WSC students experienced, the lower their study effort was. Additionally, it was found that the more WSF students reported, the more effort they put into their study. Finally, students amount of effort in their study showed to positively influence their study outcomes.

Next-after having found model fit in both the group of ethnic majority and ethnic minority students - it was investigated whether the relationships as depicted in the model (see Fig. 1) are different for ethnic minority students and ethnic majority students (RQ3). In Table 3, on lines 3 and 4 respectively, the $\chi^{2}$-values for the unconstrained and constrained simultaneous between-group analyses are presented. The between-group $\chi^{2}$-difference test (line 5) was not significant. In other words, no significant differences in relations as depicted in Fig. 2 were found between the ethnic minority and ethnic majority

Table 3 Structural equation modeling: goodness-of-fit information for within- and between-group comparisons

\begin{tabular}{llllll}
\hline Group & $\chi^{2}$ & $d f$ & $p$ & CFI & RMSEA \\
\hline Ethnic majority & 45.07 & 19 & .00 & .97 & .05 \\
Non-Western ethnic minority & 27.67 & 19 & .09 & .95 & .05 \\
Unconstrained between-group model & 72.80 & 38 & .00 & .97 & .03 \\
Constrained between-group model & 83.23 & 49 & .00 & .97 & .03 \\
$\chi^{2}$-difference & 10.43 & 11 & .49 & & \\
\hline
\end{tabular}

$N_{\text {majority }}=666 ; N_{\text {minority }}=167$

CFI Comparative Fit Index, RMSEA root mean square error approximation

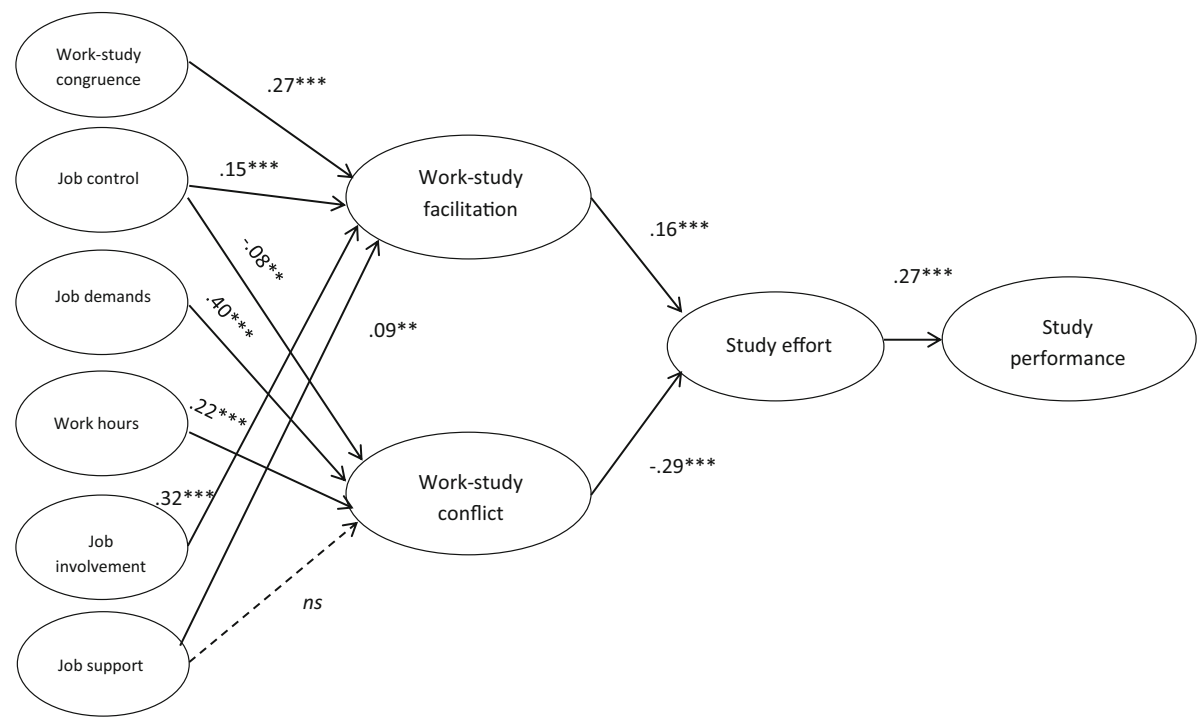

Fig. 2 Accepted path model of WSC and WSF for the full sample. Note. $\chi^{2}=55.52, d f=19, p<.01$; $\mathrm{CFI}=.97$; RMSEA $=.05(N=833) . * * p<.01 ; * * *<<.001, n s=$ not significant 
group. Therefore, $R Q 3$ - whether the relationships in the model are different for ethnic minority students and ethnic majority students-could be answered negatively.

\section{Discussion}

Combining earlier studies in the work-study domain (e.g., Butler 2007) and the familystudy domain (e.g., Meeuwisse et al. 2011, 2014), we tested whether differences between ethnic groups exist in a work-study interface model. The present study to our knowledge is the first to investigate possible differences in work-study conflict (WSC) and work-study facilitation (WSF) between ethnic minority and ethnic majority students as an explanation for the poorer study results of non-Western ethnic minority students compared to those of ethnic majority students. In this final paragraph, the results are discussed and directions for future research and practice, and study limitations are presented.

\section{Explaining differences between ethnic minority and ethnic majority students in academic outcomes from the work-study model}

The results revealed that non-Western ethnic minority students earned lower grades than ethnic majority students, confirming previous studies reporting that academic careers of ethnic minority students are less successful compared to the academic careers of ethnic majority students (Hobson-Horton and Owens 2004; Severiens and Wolff 2008; Swail et al. 2003). The present study focused on one explanation for these differences, namely whether work-study interface issues predict students' academic performance in both ethnic groups in the same way.

The accepted work-study model illustrated that students' GPA is positively affected by students' study effort. That is, the more effortful behaviors students show, the higher their grades. The model also showed that the study effort is determined negatively by WSC. In other words, the more WSC students experience, the less effortful behaviors they report. Lower conflict between work and study will therefore positively affect academic success, via effort. The model further revealed that study effort is not only influenced by WSC, but also by WSF. High levels of WSF result in more study effort, and ultimately in higher grades.

Looking at participation in work activities, it is shown that various job factors relate to WSC as well as to WSF (cf. Butler 2007; Creed et al. 2015). Job control negatively affects WSC, and job demands and number of work hours per week positively affects WSC. This means that less perceived control in students' jobs results in more conflict between the work and the study domain, and more demands in students' jobs and more work hours result in more conflict between work and study, which ultimately-via effort-leads to lower grades. Congruence between work and study, job control, job involvement, and job support positively affect WSF, which leads to more study effort and-in the end-higher grades. All structural relationships in the work-study model that were tested (see Fig. 1) are identical for non-Western ethnic minority students and ethnic majority students. However, examination of ethnic-group differences revealed that ethnic majority students report higher levels of job demands than non-Western ethnic minority students and that non-Western ethnic minority students work more hours per week than ethnic majority students. Non-Western ethnic minority students also show higher levels of WSC, less study effort and lower GPAs than ethnic majority students. 
Overall, the model of the work-study interface shows the complex interplay of work factors in explaining study success, for both ethnic minority and majority students. That is, participating in work activities seems to lead to higher levels of facilitation but also to higher levels of conflict. Students' work activities seem to contribute in achieving study success, but work-especially work that is to a lesser extent congruent with the students' course of study - at the same time also prevents students from achieving study success. In addition, a group difference exists in number of hours work, job demands, WSC, study effort and GPA. Non-Western ethnic minority students work more hours per week, leading to more WSC than ethnic majority students, and-in the end, via less study effort- to lower study outcomes.

\section{Future research and implications}

This study has several implications for research on inter-role processes and on possible differences and similarities in the relationship between work and study between ethnic groups in particular. Most research testing models on inter-role processes seemed to have used ethnic majorities. Thus, little was known about the generalizability of previous research to ethnic minorities (Butler 2007; Creed et al. 2015). The results of the present study are the first to show that the conceptual model of the work-study interface also fits the group of ethnic majority students and the group of non-Western ethnic minority students separately. It is recommended that-similar to the present study-future studies on inter-role processes systematically include tests of invariance across ethnic groups (cf. Meeuwisse et al. 2014).

The difference in study success between ethnic minority students and ethnic majority students was partly explained by average differences, but not by structural differences. Given the low percentage of explained variance, it is very well possible that external factors (that may be different for ethnic majority and minority students) offer additional explanations. In other words, even though we did not observe any structural differences in the current model, alternative models may uncover such structural differences. Further research is needed to learn more about such factors.

This study shows the importance but also the complex aspects of work in the lives of both ethnic majority and ethnic minority students in higher education. Work factors both relate to WSC and WSF. On the one hand, job demands seem to have a fairly strong influence on WSC. This means that higher levels of demands in the job that are imposed on the student have a strong relationship with conflict between work and study, which leads to lower amounts of study effort and-in the end-lower grades. On the other hand, high levels of congruence between type of job and theme or topic of study seem to systematically lead to high levels of WSF, which in turn leads to more study effort and ultimately to higher grades. Recent changes in the Netherlands will at least result in comparable work behavior for students, if not constrain students to working more hours next to studying. Since September 2015, the Dutch government abolished government student grants and replaced them by the possibility of a student loan from the government. Although, as a result of the abolishment of government student grants, the number of new students starting in their first year will not alter, it is expected that all students will be inclined to working more hours during their study (CPB 2013). Putting pressure on work behavior of students may be rather linked to more job demands and less job control than for example more job involvement or job support. This might in turn lead to more conflict between work and study, less study effort, and in the end lower academic outcomes. The presumable negative influence of the abolishment of government grants in the Netherlands 
may even impact more on the lives of ethnic minority students than on the lives of ethnic majority students, as ethnic minority students worked longer hours to begin with.

\section{Limitations}

A first limitation is that due to the relatively small number of ethnic minority participants from the different countries of origin it was impossible to examine the results for these different ethnic groups separately. Future studies will need to examine the current study's results in more detail for each separate group. In addition, it would be worth to investigate the work-study interface model in ethnic groups defined by participants' self-identification with a particular sociocultural group. This may increase the generalizability of the present study to other cultures and contexts where ethnicity, in contrast to the Netherlands, is not defined by the birthplace of one's parents.

Secondly, this study is limited by its cross-sectional design. Therefore, it is impossible to make causal inferences regarding relations among the model constructs. A longitudinal design is needed to learn more about how work life affects student life over a longer period of time. For instance, a longitudinal study conducted by Warren et al. (2000) showed that poorer results of high-school students resulted in more hours of work by these students. They explained that students who do not perceive that they will be academically successful and who are not confident about their chances of going to college turn to employment as a more fruitful way to spend their time and energy. These students may perceive that paid employment is more promising as an avenue of success, in both the short- and long-term. For them, working a lot may seem like the best way to prepare for life after high school (Warren et al. 2000). Although research has found that long hours spent working (usually over $20 \mathrm{~h}$ a week) were associated with poorer study skills and poorer academic performance (Lammers et al. 2001; Lens et al. 2005; Trockel et al. 2000), results of Warren et al. (2000) show that it may very well work the other way around, i.e., poor academic performance leads to more hours of work per week.

\section{Conclusion}

Investigating the differential effect of the study-life domain and the work-life domain on study outcomes of non-Western ethnic minority students and ethnic majority students, we tested a model of the work-study interface in a sample of ethnic minority and majority students from a major Dutch university $(N=833)$. Results showed that work factors led to both WSC and WSF, which in turn led to lower respectively higher study effort and GPA. The structural relationships, as depicted in the conceptual model of work-study interface, were similar for both the group of non-Western ethnic minority students and the group of ethnic majority students. We did see, however, that ethnic minority students work more hours per week, which may partly explain-via higher levels of WSC and lower study effort-the lower study outcomes for this group. 


\section{Appendix: Individual scale items}

Job control

1. I have freedom to decide how to organize my work

2. I have control over what happens on my job

3. I can make my own decisions on my job

4. I have freedom to decide which tasks to do on my job

Job demands

1. My job requires me working hard

2. My job requires a great deal of work to be done

3. There is not enough time to do my job

4. There is excessive work in my job

5. There is not enough time to finish my work

6. There are conflicting demands on my job

Job involvement

1. The most important things in my life happen at work

2. The most important things that happen to me involve my job

3. I have other activities more important than my work $(r)^{2}$

4. To me my work is only a small part of who I am (r)

5. I am involved personally in my work

6. Most things in life are more important than work (r)

Job support

1. Certain colleagues come to me when they have problems or need advice at work

2. I need my colleagues for (emotional) support at work

3. Colleagues share many of my interests

4. My colleagues and I are open about what we think about things

5. Colleagues come to me for (emotional support)

6. Colleagues are good at helping me solve problems at work

7. I have a deep sharing relationship with a number of colleagues

8. Colleagues seek me out for companionship

Work-study facilitation (WSF)

1. The things I do at work help me deal with personal and practical issues at university

2. The things I do at work make me a more interesting person at university

3. The skills I use at work are useful for my university studies

4. Having a good day at work makes me a better person at university

5. What I learn at work is valuable for my university studies

6. My job gives me a more positive attitude at university

7. My job makes me enjoy my course program more

8. I like studying because of my job

9. My job makes that I take pleasure in studying

2 Items marked with an $(r)$ were reverse scored. 
Work-study conflict (WSC)

1. Because of my job, I go to university tired

2. I spend less time studying and doing homework because of my job

3. My job takes up time that I'd rather spend at university or on assignments for my studies

4. I have to miss study activities due to the amount of time I must spend on work responsibilities

5. When I study I keep thinking of work-related issues

6. My attention slackens while studying because stuff at work worries me

7. I am often so emotionally drained when I get home from work that it prevents me from contributing to my schoolwork

8. Due to all the pressures at work, sometimes when I come home I am too stressed to do the things I should do on schoolwork

9. My study suffers from my stressful job

10. The problem-solving behaviors I use in my job are ineffective in resolving problems at university

11. Behavior that is effective and necessary for me at work would be counterproductive at university

12. I need to behave differently at university compared to how I need to behave at work

13. How I am at work is undesirable at university

Study effort

1. I put forth a high level of effort in class

2. I concentrate hard in class

3. I let my mind wander in class $(r)$

4. I try to do my best on all assignments

5. I really study hard for exams

6. I do the best possible schoolwork I can

7. I do just enough schoolwork to get by $(r)$

8. I do all of the reading assigned for class

9. I turn in some assignments late $(r)$

\section{References}

Arbuckle, J. L., \& Wothke, W. (1999). Amos 4.0 users guide. Chicago, IL: Smallwaters Co.

Barnett, R. C., \& Hyde, J. S. (2001). Women, men, work, and family. An expansionist theory. American Psychologist, 56, 781-796.

Beerkens, M., Mägi, E., \& Lill, L. (2011). University studies as a side job: Causes and consequences of massive student employment in Estonia. Higher Education, 61(6), 679-692.

Butler, A. B. (2007). Job characteristics and college performance and attitudes: A model of work-school conflict and facilitation. Journal of Applied Psychology, 92(2), 500-510.

Butler, A. B., Grzywacz, J. G., Bass, B. L., \& Linney, K. D. (2005). Extending the demands-control model: A daily diary study of job characteristics, work-family conflict and work-family facilitation. Journal of Occupational and Organizational Psychology, 78, 155-169.

Byrne, B. M. (2001). Structural equation modeling with Amos. Basic concepts, applications, and programming. Mahwah, NJ: Lawrence Erlbaum Associates.

Byrne, B. M. (2004). Testing for multigroup invariance using Amos graphics: A road less traveled. Structural Equation Modeling: A Multidisciplinary Journal, 11(2), 272-300. 
Callender, C. (2008). The impact of term-time employment on higher education students' academic attainment and achievement. Journal of Educational Policy, 23, 359-377.

Carlson, D. S., Kacmar, K. M., \& Williams, L. J. (2000). Construction and initial validation of a multidimensional measure of work-family conflict. Journal of Vocational Behavior, 56(2), 249-276.

Central Plan Bureau (CPB). (2013). CPB Notitie. Aflossing studieschuld bij sociaal leenstelsel [CPB Note. Repayment student debt of social feudal system]. The Hague: The Netherlands.

Cohen, J. (1988). Statistical power analysis for the behavioral sciences (2nd ed.). Hillsdale, NJ: Lawrence Erlbaum Associates Inc.

Creed, P. A., French, J., \& Hood, M. (2015). Working while studying at university: The relationship between work benefits and demands and engagement and well-being. Journal of Vocational Behavior, $86,48-57$.

Derous, E., \& Ryan, A.-M. (2008). When earning is beneficial for learning: The relation of employment and leisure activities to academic outcomes. Journal of Vocational Behavior, 73, 118-131.

Eldering, L. (1997). Ethnic Minority Students in the Netherlands from a cultural-ecological perspective. Anthropology \& Education Quarterly, 28(3), 330-350.

Ford, M. T., Heinen, B. A., \& Langkamer, K. L. (2007). Work and family satisfaction and conflict: A metaanalysis of cross-domain relations. Journal of Applied Psychology, 92(1), 57-80.

Frone, M. R., Russell, M., \& Cooper, M. L. (1992). Antecedents and outcomes of work-family conflict: Testing a model of the work-family interface. Journal of Applied Psychology, 77(1), 65-78.

Greenhaus, J. H., \& Powell, G. N. (2006). When work and family are allies: A theory of work-family enrichment. Academy of Management Review, 31, 72-92.

Hiemstra, A. M. F., Derous, E., Serlie, A. W., \& Born, M Ph. (2013). Ethnicity effects in graduates' resume content. Applied Psychology: An International Review, 62(3), 427-453.

Hobson-Horton, L. D., \& Owens, L. (2004). From freshman to graduate: Recruiting and retaining minority students. Journal of Hispanic Higher Education, 3, 86-107.

Hofman, W. H. A., \& Van den Berg, M. N. (2003). Ethnic-specific achievements in Dutch higher education. Higher Education in Europe, 28(3), 371-389.

Hoving, I., Dibbits, H., \& Schrover, M. (2005). Cultuur en migratie in Nederland. Veranderingen van het alledaagse 1950-2000 [Culture and migration in The Netherlands. Changes of everyday life 1950-2000]. The Hague, The Netherlands: Sdu Uitgevers.

Hu, L., \& Bentler, P. M. (1999). Cutoff criteria for fit indexes in covariance structure analysis: Conventional criteria versus new alternatives. Structural Equation Modeling, 6(1), 1-55.

IBM SPSS Amos. (2011). Amos 20.0.0 [software application]. Meadville, PA: Amos Development Co.

Jennissen, R. (2006). Allochtonen in het hoger onderwijs [Minorities in higher education]. DEMOS, 22, $65-68$.

Jennissen, R. P. W. (2011). De Nederlandse migratiekaart. Achtergronden en ontwikkelingen van verschillende internationale migratietypen. [The Dutch migration monitor. Backgrounds and developments of different types of international migration]. The Hague: WODC, CBS, BJU.

Kahn, R. L., Wolfe, D. M., Quinn, R., Snoek, J. D., \& Rosenthal, R. A. (1964). Organizational stress. New York: Wiley.

Kuh, G. D., Kinzie, J., Buckley, J. A., Bridges, B. K., \& Hayek, J. S. (2006). What matters to student success: A review of the literature. (National Postsecondary education report 1-151). Washington, DC: National Postsecondary Education Cooperative.

Lammers, W. J., Onwuegbuzie, A. J., \& Slate, J. R. (2001). Academic success as a function of gender, class, age, study habits, and employment of college students. Research in the Schools, 8, 71-81.

Lens, W., Lacante, M., Vansteenkiste, M., \& Herrera, D. (2005). Study persistence and academic achievements a function of type of competing tendencies. European Journal of Psychology and Education, 20(3), 275-287.

Lucassen, J. (2005). Appendix. Een kort overzicht van de immigratie naar Nederland in de twintigste eeuw [Appendix. A short overview of the immigration into The Netherlands in the 20th century]. In I. Hoving, H. Dibbits, \& M. Schrover (Eds.), Cultuur en migratie in Nederland. Veranderingen van het alledaagse 1950-2000 [Culture and migration in The Netherlands. Changes of everyday life 1950-2000] (pp. 415-428). The Hague, The Netherlands: Sdu Uitgevers.

Lucassen, J., \& Penninx, R. (1994). Nieuwkomers, nakomelingen, Nederlanders. Immigranten in Nederland 1550-1993 [Newcomers, descendants, Dutchmen. Immigrants in The Netherlands 1550-1993]. Amsterdam: Het Spinhuis.

MacCallum, R. C., Browne, M. W., \& Sugawara, H. M. (1996). Power analysis and determination of sample size for covariance structure modeling. Psychological Methods, 1(2), 130-149.

Markel, K. S., \& Frone, M. R. (1998). Job characteristics, work-school conflict, and school outcomes among adolescents: Testing a structural model. Journal of Applied Psychology, 83, 277-287. 
Meeuwisse, M., Born, M Ph, \& Severiens, S. E. (2011). The family-study interface and academic outcomes: Testing a structural model. Journal of Educational Psychology, 103(4), 982-990.

Meeuwisse, M., Born, M Ph, \& Severiens, S. E. (2014). The family-study interface and academic outcomes: Differences and similarities between ethnic minority and ethnic majority students. Cultural Diversity \& Ethnic Minority Psychology, 20(3), 401-412.

Procidano, M. E., \& Heller, K. (1983). Measures of perceived social support from friends and from family: Three validation studies. American Journal of Community Psychology, 11, 1-24.

Pryor, J. H., Hurtado, S., Saenz, V. B., Santos, J. L., \& Korn, W. S. (2007). The American Freshman: Forty year trends. Los Angeles: Higher Education Research Institute, UCLA.

Reeve, C. L., \& Smith, C. S. (2001). Refining Lodahl and Kejner's job involvement scale with a convergent evidence approach: Applying multiple methods to multiple samples. Organizational Research Methods, 4, 91-111.

Richardson, J. T. E. (2008). The attainment of ethnic minority students in UK higher education. Studies in Higher Education, 33, 33-48.

Riggert, S. C., Boyle, M., Petrosko, J. M., Ash, D., \& Rude-Parkins, C. (2006). Student employment and higher education: Empiricism and contradiction. Review of Educational Research, 76(1), 63-92.

Severiens, S. E., \& Wolff, R. (2008). A comparison of ethnic minority and majority students: Social and academic integration, and quality of learning. Studies in Higher Education, 33(3), 253-266.

Statistics Netherlands. (2014). Jaarrapport Integratie 2014 [Annual Report Integration 2014]. The Hague/ Heerlen: The Netherlands, CBS.

Swail, W. S., Redd, K. E., \& Perna, L. W. (2003). Retaining minority students in higher education: A framework for success. ASHE-ERIC Higher Education Report, 30(2), 1-187.

Tang, S., Siu, O. L., Cheung, F. (2012). A study of work-family enrichment among Chinese employees: The mediating role between work support and job satisfaction. Applied Psychology: An International Review. doi:10.1111/j.1464-0597.2012.00519.x.

Trockel, M. T., Barnes, M. D., \& Egget, D. L. (2000). Health-related variables and academic performance among first-year college students: Implications for sleep and other behaviors. Journal of American College Health, 49, 125-131.

U.S. Department of Education, National Center for Education Statistics. (2006). Profile of undergraduates in U.S. postsecondary institutions: 2003-04 (NCES publication no. 2006-184). Washington, DC: IES.

Van der Burg, D., Kreetz, D., \& Van der Schors, A. (2012). Nibud Studentenonderzoek 2011-2012. Report. Utrecht, The Netherlands: Nibud.

Vandenberg, R. J., \& Lance, C. E. (2000). A review and synthesis of the measurement invariance literature: Suggestions, practices, and recommendations for organizational research. Organizational Research Methods, 3(1), 4-70.

Vogel, J. (2005). Cultuur en migratie in Nederland. Nabije vreemden [Culture and migration in The Netherlands. Near strangers]. The Hague, The Netherlands: Sdu Uitgevers.

Warren, J. R., LePore, P. C., \& Mare, R. D. (2000). Employment during high school: Consequences for students' grades in academic courses. American Educational Research Journal, 37(4), 943-969. 